\title{
Post-partum labial adhesion-a case report
}

\section{Shamrao Ramji Wakode, Varsha Narayana Bhat*}

Department of Obstetrics and Gynaecology, Dr SCGMC. Nanded, Maharashtra, India

Received: 13 April 2021

Accepted: 05 May 2021

\section{*Correspondence:}

Dr. Varsha Narayana Bhat,

E-mail: chvarshanbhat@gmail.com

Copyright: ( $\odot$ the author(s), publisher and licensee Medip Academy. This is an open-access article distributed under the terms of the Creative Commons Attribution Non-Commercial License, which permits unrestricted non-commercial use, distribution, and reproduction in any medium, provided the original work is properly cited.

\section{ABSTRACT}

A 22 years old primipara presented after 1.5 years of uncomplicated normal vaginal delivery with complaints of difficulty during intercourse and inability to conceive. Examination revealed labial adhesion connecting left and right labia minora with only $5 \mathrm{~mm}$ pinhole opening at the posterior end. Surgical division under anaesthesia resulted in successful complete recovery.

Keywords: Labial adhesion, Post-partum, Surgical lysis

\section{INTRODUCTION}

Even though the exact cause for labial adhesion remains unknown, it is believed that hypoestrogenic state may be a contributing factor. It is rare in reproductive age group. ${ }^{1-3}$

Those who develop labial adhesion during reproductive age group history of genital trauma or irritation to genitalia has to be considered. It is reported that $80 \%$ of cases resolve without any treatment, but symptomatic individuals may require surgical lysis of adhesions as well as topical estrogen application. ${ }^{4-6}$ Postpartum adhesions are rarely described in medical literature so far.

\section{CASE REPOERT}

A 22 years old primipara whose last child was 1 years old presented to gynaecology OPD with complaints of difficulty during intercourse, lack of sexual satisfaction during intercourse and inability to conceive. She did not have any urinary complaints. Her last pregnancy was supervised at our hospital where she had delivered a male baby of $2.7 \mathrm{~kg}$ by normal vaginal delivery with a left mediolateral episiotomy. She appeared healthy on general physical examination. Fusion of labia minora with only a $5 \mathrm{~mm}$ pinhole opening at the posterior end (Figure 1) was noted on inspection of genitalia. A longitudinal vaginal septum with an opening on anterior fourchette in close relation with urethra. Vagina and cervix were not visualised (Figure 1). There was a septum that has formed the pouch admitting about $2-3 \mathrm{~cm}$ of the examining finger (Figure 2). Haematological investigations and pelvic ultrasound were within normal limit. No evidence of hematometra or hematocolpos. Patient was counselled on her diagnosis. Consented to examination and repair under anaesthesia. Surgeon had done a sharp dissection of the pouch (Figure 4) and edges of the incision were repaired using vicryl 2/0 (Figure 5), separated using a wax mould (Figure 6). She did well subsequently and was discharged on post-operative day 3. She was followed up for next 6 months with no further complaints.

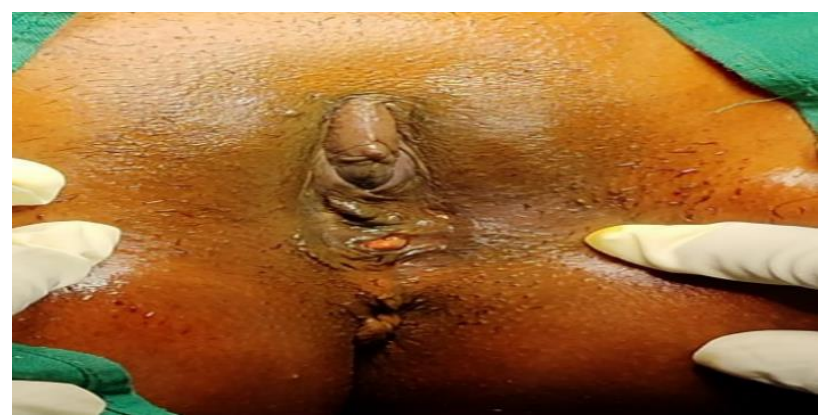

Figure 1: Labial adhesion with area of healed left mediolateral episiotomy. 


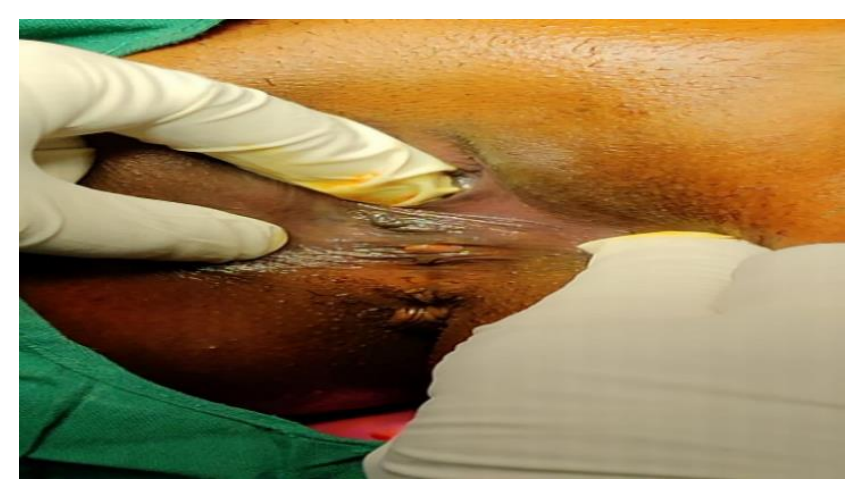

Figure 2: Index finger in the pouch formed by labial septum.

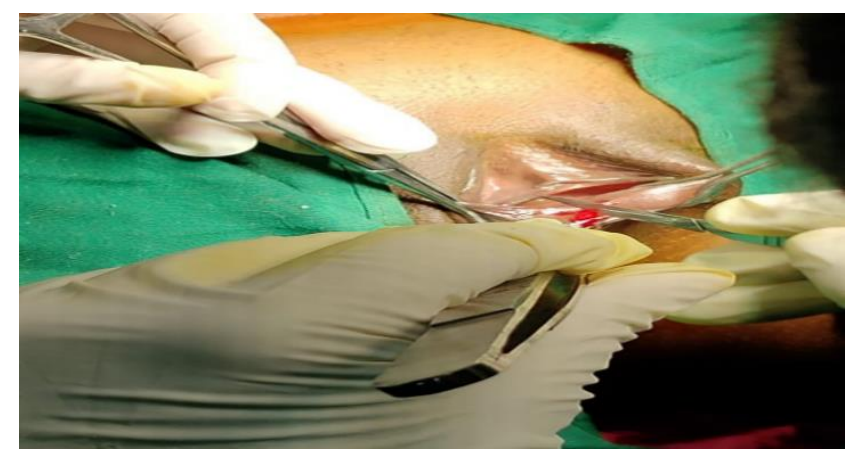

Figure 3: Sharp dissection of septum of normal vaginal mucosa.

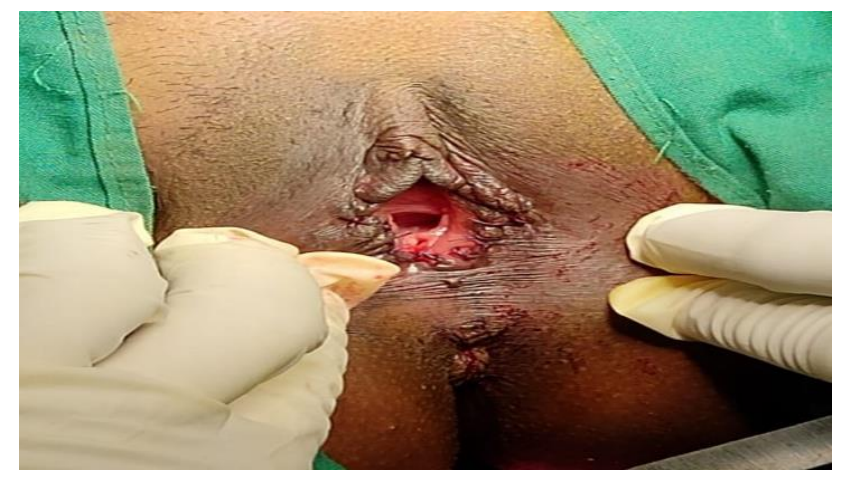

Figure 4: Egdes of the incision repaired by vicryl 2/0.

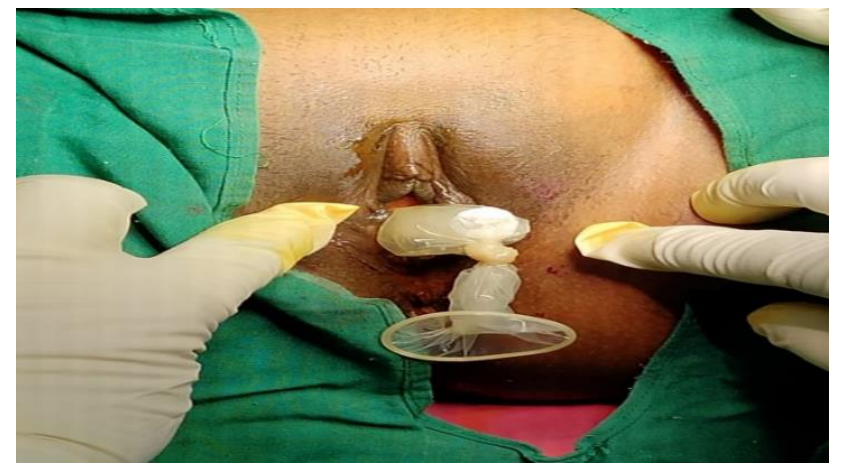

Figure 5: Vaginal mould kept in situ to prevent refusion.

\section{DISCUSSION}

Optimum perineal care after delivery has been practiced widely over the years. In our case patient was instructed modern perineal care which had included sitz bath, labial separation during urination and periodical perineal cleansing. As there are no documentation regarding labial tears or laceration in our case, poor hygienic care, and neglected position might have resulted in close apposition of vulva as well as an exclusive breast feeding which resulted in raised prolactin levels in turns a hypoestrogenic state could be the relevant factors resulted in above complication. Difficulty in resuming sexual activity was the major complaint ${ }^{7}$ as in our case. As patient was symptomatic and adhesion was wide surgical lysis ${ }^{8}$ was done as definite treatment in our case.

\section{CONCLUSION}

Postpartum labial adhesions are rarely reported in literature even though incidence may be higher that estimated cases. Good hygienic practices, early resumption to sexual activity once patient is comfortable as well patient's education regarding episiotomy care will prevent the labial adhesion formation. Labial adhesions should be managed by an interprofessional team which include doctor, nursing staff and primary care provider to have better outcome. Surgical resection under anaesthesia and reassurance should be attempted as first line therapy for postpartum labial adhesion.

\section{Funding: No funding sources \\ Conflict of interest: None declared \\ Ethical approval: Not required}

\section{REFERENCES}

1. Norris JE, Elder CV, Dunford AM, Rampal D, Cheung C, Grover SR. Spontaneous resolution of labial adhesions in pre-pubertal girls. J Paediatr Child Health. 2018;54(7):748-53.

2. Rubinstein A, Rahman G, Risso P, Ocampo D. Labial adhesions: Experience in a children's hospital. Arch Argent Pediatr. 2018;116(1):65-8.

3. Fernandez S. A paediatrician's Take on a Few Common Infant Urologic and Gynecologic Issues. Pediatr Ann. 2017;46(11):e397-9.

4. Knudtzon S, Haugen SE, Myhre AK. Labial adhesion-diagnostics and treatment. Tidsskr Nor Laegeforen. 2017;137(1):31-5.

5. Vilano SE, Robbins CL. Common prepubertal vulvar conditions. Curr Opin Obstet Gynecol. 2016;28(5):359-65.

6. Bussen S, Eckert A, Schmidt U, Sütterlin M. Comparison of Conservative and Surgical Therapy Concepts for Synechia of the Labia in Pre-Pubertal Girls. Geburtshilfe Frauenheilkd. 2016;76(4):390-95.

7. Sharma B, Arora R, Preston J. Postpartum labial adhesions following normal vaginal delivery. J Obstet Gynaecol. 2005;25(2):2. 
8. Caglayan EK. A rare complication of vaginal delivery: labial adhesion. Clin and Experimental Obstet Gynecol. 2013;41(1):98-9.
Cite this article as: Wakode SR, Bhat VN. Postpartum labial adhesion-a case report. Int $\mathbf{J}$ Reprod Contracept Obstet Gynecol 2021;10:2528-30. 